\title{
Correlation between placental location and development of preeclampsia
}

\author{
Prashaant Uikey $^{1}$, Vaishali Gurwani ${ }^{1 *}$, Megha Tajne ${ }^{2}$
}

\begin{abstract}
${ }^{1}$ Department of Obstetrics and Gynecology, Indira Gandhi Government Medical College, Nagpur, Maharashtra, India ${ }^{2}$ Department of Anaesthesiology, NKP Salve Institute of Medical Sciences, Nagpur, Maharashtra, India
\end{abstract}

Received: 30 August 2019

Accepted: 30 September 2019

\author{
*Correspondence: \\ Dr. Vaishali Gurwani, \\ E-mail: vaishaligurwani@gmail.com
}

Copyright: () the author(s), publisher and licensee Medip Academy. This is an open-access article distributed under the terms of the Creative Commons Attribution Non-Commercial License, which permits unrestricted non-commercial use, distribution, and reproduction in any medium, provided the original work is properly cited.

\begin{abstract}
Background: Preeclampsia occurs in presence of placenta. Blood supply distribution within the uterus is not similar in central versus lateral sites implicating that, the site of placenta is likely to have a profound effect on the pregnancy outcome. In the light of these observations, a prospective study was designed to find out if the lateral location of placenta as seen by ultrasound between 18-24 weeks of gestation can be used to predict the development of preeclampsia.

Methods: This prospective study was conducted in the department of Obstetrics and Gynaecology in IGGMC, Nagpur between January 2017 and June 2018. Pregnant women, with singleton pregnancy and without any risk factor, attending the antenatal clinic were subjected to USG between 18-24 weeks of gestation. Accordingly, patients were divided into 2 groups, 51 with lateral placenta and 51 with central placenta. All 102 women were followed till term. The end point of the study was development of preeclampsia i.e. BP >140/90 and urine albumin $>300 \mathrm{mg}$ in 24 hours sample. The data obtained was analysed using appropriate statistical tests.

Results: Out of 102 patients, $80.9 \%$ were from lateral placenta group and only $19.1 \%$ were from central placenta. Sensitivity of this as screening test for preeclampsia was $80.9 \%$ while specificity was $58 \%$, Odds ratio being 5.875 . In predicting preeclampsia, lateral placenta had a meaningful effect with $\mathrm{p}$ value $<0.001$.

Conclusions: Placental laterality, as determined by USG between 18-24 weeks of gestation, is a simple and costeffective screening test for development of preeclampsia.
\end{abstract}

Keywords: Central placenta, Perinatal outcome, Placental laterality, Preeclampsia, Screening test, Ultrasonography

\section{INTRODUCTION}

Preeclampsia is defined as new onset hypertension with systolic blood pressure of more than $140 \mathrm{mmHg}$ and diastolic pressure of $90 \mathrm{~mm} \mathrm{Hg}$ after 20 weeks of gestational age together with proteinuria (more than $0.3 \mathrm{~g} / 24$ hours), which could complicate $5 \%$ to $8 \%$ of all pregnancies and if remained untreated leads to major mortality and morbidity. ${ }^{1}$ Various screening tests have been studied and advocated till time for early detection of preeclampsia. Few of them are invasive and very costly and the others are not reliable or cost effective.

Authors, therefore, need a test that would screen and detect women at high risk for developing preeclampsia so that prophylactic therapies can be started easily. In preliminary investigations by Wood et al in 1962 and Friedman et al in 1964, different methods, such as X-ray imaging of soft tissue, were used to determine placental location and their potential association with preeclampsia. ${ }^{2,3}$ By emergence of sonography, different 
investigations have been performed to assess the association between the locations of lateral placenta and occurrence of preeclampsia in pregnancy. There has always been a need for a screening test that is easy to perform, is cost effective and non-invasive, to detect preeclampsia at an early stage which could prevent a huge bulk of mortality and morbidity associated with preeclampsia. $^{4}$

Preeclampsia occurs only in the presence of placenta. ${ }^{5}$ The poorly perfused placenta may be vasculature and cause endothelial cell dysfunction. Reduced placental perfusion in preeclampsia is thought to result from failure of the trophoblast invade maternal spiral arteries. And therefore, preeclampsia and eclampsia can be prevented when diagnosed early. ${ }^{6,7}$

Blood supply distribution within the uterus is not of a similar form in central versus lateral sites implicating that site of implantation and resultant location of the placenta are likely to have a profound effect on the pregnancy outcome. $^{8-13}$

When placenta is centrally located, the utero-placental needs are met with by equal distribution of both the uterine arteries. However, when placenta is laterally located, in majority of cases the utero-placental blood flow needs are met primarily with one of the uterine arteries and with some contribution from the other uterine artery by collateral circulation. The degree of collateral circulation may not be the same in all subjects and deficient contribution may facilitate development of preeclampsia and IUGR. ${ }^{6,7,14}$ In the light of these observations, we designed a prospective study to find out whether the lateral location of placenta as seen by ultrasound at 18-24 weeks of gestation can be used to predict the development of preeclampsia.

The objectives of this study were to study the correlation between placental location and development of preeclampsia. To compare the perinatal outcome in both the groups.

\section{METHODS}

This prospective observational study was conducted in the department of Obstetrics and Gynaecology in IGGMC, Nagpur between January 2017 and June 2018. Pregnant women, with singleton pregnancy and without any risk factor, attending the antenatal clinic were subjected to USG between 18-24 weeks of gestation for placental localization after fulfilling the patient selection criteria.

\section{Inclusion criteria}

- The gestational age between 18-24 weeks

- Women who intend to have their deliveries at IGGMC, Nagpur

- $\quad$ Singleton pregnancy.

\section{Exclusion criteria}

- History of chronic hypertension

- History of diabetes mellitus

- History of renal disease

- Blood pressure $>140 / 90 \mathrm{mmHg}$ (prior to onset of study)

- Evidence of proteinuria by the dipstick method (prior to onset of study)

- Patient with multiple gestation and uterine anomalies.

- History of smoking

- Not willing for follow up.

The placenta was classified as central when it was equally distributed between the right and the left side of the uterus irrespective of anterior, posterior or fundal position. When $75 \%$ or more of the placental mass was to one side of the midline, it was classified as unilateral right or left placenta. All the ultra-sonograms were done by a single individual to avoid any error. Amongst the pregnant women subjected to USG, 51 women having central placenta were put in one group and 51 with lateral placenta were put in another group.

All 102 pregnant women were subjected to thorough clinical examination and laboratory investigations and patients were advised for regular follow as per hospital protocol. BP and proteinuria were measured in every subsequent visit along with other required investigations. BP measurement was done using mercury sphygmomanometer and bell of stethoscope, in right arm in supine position to hear the Korotkoff V sound. Patients were required to follow up monthly till 28 weeks and fortnightly till 36 weeks of gestation and weekly there after till term. Patients who developed preeclampsia were followed up more frequently as per the need and condition of patient. The end point of the study was the development of preeclampsia as per the ACOG criteria of delivery, which is BP reading more than 140/90 and urine albumin of $>300 \mathrm{mg}$ in 24-hour sample or 1+ on dipstick. Women who developed preeclampsia were managed according to the hospital protocol. Patients in both the groups were followed up till delivery to note their perinatal outcome. The data thus obtained was analyzed using appropriate statistical tests.

There were no procedural risk factors for the patient and no adverse drug reactions. Ethical clearance from institutional ethics committee was obtained.

\section{RESULTS}

The $\mathrm{p}$ value of age and parity was $>0.05$, thus these parameters were not significant. Both the groups were statistically comparable in terms of distribution of patients as per age and gravida status.

Most of the patients developing preeclampsia, (80.9\%) had laterally located placenta. Only $19.1 \%$ of patients 
with preeclampsia had central placenta. Out of 21 women developing preeclampsia, 18 women $(85.7 \%)$ were in the age group $19-30$ years, only 2 women $(9.5 \%)$ were $<18$ years of age and 1 woman $(4.7 \%)$ was above 30 years of age.
Out of 21 patients developing preeclampsia, $16(76.19 \%)$ were primigravida, $3(14.28 \%)$ were gravida 2 and 2 $(9.52 \%)$ were gravida $3+$ thus showing highest incidence of preeclampsia amongst primigravida.

Table 1: Distribution of total patients in both the study groups according to age.

\begin{tabular}{|llll|}
\hline Age & $<18$ years & $19-30$ years & $>30$ years \\
\hline Central placenta $(51)$ & 6 & 34 & 11 \\
\hline Lateral placenta $(51)$ & 4 & 39 & 8 \\
\hline Total $(\mathbf{1 0 2})$ & $\mathbf{1 0}(\mathbf{9 . 8 \%})$ & $\mathbf{7 3}(\mathbf{7 1 . 6 \% )}$ & $\mathbf{1 9}(\mathbf{1 8 . 6 \% )}$ \\
\hline
\end{tabular}

Table 2: Distribution of patients as per gravida status in each group.

\begin{tabular}{|llll|}
\hline Group & Primigravida & Gravida 2 & Gravida 3+ \\
\hline Central (51) & $32(62.7 \%)$ & $9(17.6 \%)$ & $10(19.6 \%)$ \\
\hline Lateral $(51)$ & $29(56.8 \%)$ & $10(19.6 \%)$ & $12(23.5 \%)$ \\
\hline Total $(\mathbf{1 0 2})$ & $\mathbf{6 1}(\mathbf{5 9 . 8 \% )}$ & $\mathbf{1 9}(\mathbf{1 8 . 6 \% )}$ & $\mathbf{2 2}(\mathbf{2 1 . 5 \% )}$ \\
\hline
\end{tabular}

Table 3: Relationship between placental location and development of preeclampsia.

\begin{tabular}{|llll|}
\hline Group & Preeclampsia & Normotensive & Total \\
\hline Central placenta (51) & 4 & 47 & 51 \\
\hline Lateral placenta (51) & 17 & 34 & 51 \\
\hline Total (102) & $\mathbf{2 1}$ & $\mathbf{8 1}$ & $\mathbf{1 0 2}$ \\
\hline
\end{tabular}

Table 4: Distribution of patients with preeclampsia according to age.

\begin{tabular}{|llll|}
\hline Age & $<18$ years & $19-30$ years & $>30$ years \\
\hline Central placenta $(4)$ & 1 & 3 & 0 \\
\hline Lateral placenta $(17)$ & 1 & 15 & 1 \\
\hline Total $(\mathbf{2 1})$ & $\mathbf{2}(\mathbf{9 . 5 \% )}$ & $\mathbf{1 8}(\mathbf{8 5 . 7 \% )}$ & $\mathbf{1}(\mathbf{4 . 7 \% )}$ \\
\hline
\end{tabular}

Table 5: Distribution of patients who developed preeclampsia as per gravida status in each group.

\begin{tabular}{|llll|}
\hline Group & Primigravida & Gravida 2 & Gravida 3+ \\
\hline Central placenta (4) & 4 & 0 & 0 \\
\hline Lateral placenta (17) & 12 & 3 & 2 \\
\hline Total (21) & $\mathbf{1 6}$ & $\mathbf{3}$ & $\mathbf{2}$ \\
\hline
\end{tabular}

Table 6: Distribution of patients according to severity of preeclampsia in each group.

\begin{tabular}{|llll|}
\hline Severity of preeclampsia & Central placenta & Lateral placenta & Total \\
\hline Mild preeclampsia & $3(18.75 \%)$ & $13(81.25 \%)$ & 16 \\
\hline Severe preeclampsia & $1(20 \%)$ & $4(80 \%)$ & 5 \\
\hline Total & $\mathbf{4}$ & $\mathbf{1 7}$ & $\mathbf{2 1}$ \\
\hline
\end{tabular}

Among 5 patients developing severe preeclampsia, 4 $(80 \%)$ were in the group with laterally located placenta and only $1(20 \%)$ were in group with central placenta. This shows that laterality of placenta not only predisposes for preeclampsia but also increases the severity of disease. Out of 24 patients having preterm delivery, 15 $(62.5 \%)$ were in the group with laterally located placenta and only $9(31.5 \%)$ were with central placenta.
Out of 17 patients with lateral placenta who developed preeclampsia, $11(64.7 \%)$ had preterm delivery and 6 (35.3\%) had term delivery. Thus, suggesting higher incidence of preterm delivery in patients with lateral placenta due to higher predisposition of preeclampsia in this group. Out of the 35 patients requiring LSCS, $62.8 \%$ were with laterally located placenta and $37.2 \%$ with central placenta. Clear predisposition for maternal and 
foetal risk is seen associated with group with lateral

placenta.

Table 7: Distribution of total patients having term/preterm delivery in both the groups.

\begin{tabular}{|llll|}
\hline Timing of delivery & Term delivery $(>37$ completed weeks) & Preterm delivery $(<37$ completed weeks $)$ & Total \\
\hline Central placenta & $42(53.8 \%)$ & $9(31.5 \%)$ & 51 \\
\hline Lateral placenta & $36(46.2 \%)$ & $15(62.5 \%)$ & 51 \\
\hline Total & $\mathbf{7 8}$ & $\mathbf{2 4}$ & $\mathbf{1 0 2}$ \\
\hline
\end{tabular}

Table 8: Perinatal outcome in terms of preterm delivery in patients with preeclampsia: Distribution of patients in both the groups.

\begin{tabular}{|llll|}
\hline Timing of delivery & Term delivery $(>37$ completed weeks) & Preterm delivery $(<37$ completed weeks) & Total \\
\hline Central placenta & $2(50 \%)$ & $2(50 \%)$ & 4 \\
\hline Lateral placenta & $6(35.3 \%)$ & $11(64.7 \%)$ & 17 \\
\hline Total & $\mathbf{8}$ & $\mathbf{1 3}$ & $\mathbf{2 1}$ \\
\hline
\end{tabular}

Table 9: Distribution of patients in both the groups according to mode of termination of pregnancy (vaginal delivery/LSCS).

\begin{tabular}{|llll|}
\hline Mode of termination & Vaginal delivery & LSCS & Total \\
\hline Central placenta & $38(56.7 \%)$ & $13(37.2 \%)$ & 51 \\
\hline Lateral placenta & $29(43.28 \%)$ & $22(62.8 \%)$ & 51 \\
\hline Total & $\mathbf{6 7}$ & $\mathbf{3 5}$ & $\mathbf{1 0 2}$ \\
\hline
\end{tabular}

Table 10: APGAR Scoring at 1 min of babies born to patients in both the groups.

\begin{tabular}{|llll|}
\hline APGAR score & $7-10($ excellent) & $4-6($ moderate) & $<3($ poor $)$ \\
\hline Central placenta & $49(53.2 \%)$ & $2(25 \%)$ & - \\
\hline Lateral placenta & $43(46.7 \%)$ & $6(75 \%)$ & $2(100 \%)$ \\
\hline Total & $\mathbf{9 2}$ & $\mathbf{8}$ & $\mathbf{2}$ \\
\hline
\end{tabular}

Table 11: APGAR Scoring of babies at 5 minutes born to patients in both the groups.

\begin{tabular}{|llll|}
\hline APGAR score & $7-10($ excellent) & $4-6($ moderate) & $<$ (poor) \\
\hline Central placenta & $50(52.7 \%)$ & $1(20 \%)$ & - \\
\hline Lateral placenta & $45(47.3 \%)$ & $4(80 \%)$ & $2(100 \%)$ \\
\hline Total & $\mathbf{9 5}$ & $\mathbf{5}$ & $\mathbf{2}$ \\
\hline
\end{tabular}

Table 12: Distribution according to NICU admission for babies of patients in both the groups.

\begin{tabular}{|lll|}
\hline NICU admission & Required & Not required \\
\hline Central placenta & $1(14.3 \%)$ & $50(52.6 \%)$ \\
\hline Lateral placenta & $6(85.7 \%)$ & $45(47.4 \%)$ \\
\hline Total & $\mathbf{7}$ & $\mathbf{9 5}$ \\
\hline
\end{tabular}

All the babies with poor APGAR score at 1 min were born to mothers with laterally located placenta. $75 \%$ of babies with moderate APGAR Score were born to patients with laterally located placenta.53.2\% of babies with excellent APGAR scoring at $1 \mathrm{~min}$ were born to mothers with central placenta thus suggesting poor perinatal outcome associated with mothers with lateral placenta.
All the babies with poor APGAR score at 5 minutes belonged to the patients with lateral placenta, while 4 (80\%) with moderate APGAR Score were also born to patients with lateral placenta. $50(52.7 \%)$ babies that had excellent APGAR scoring at 5 minutes belonged to mothers with central placenta.

Out of the 7 babies admitted in NICU, $6(85.7 \%)$ belonged to mothers with laterally located placenta. 
Table 13: Distribution of babies according to their birth weight born to patients in both the groups.

\begin{tabular}{|lllll|}
\hline Birth weight of babies & $\begin{array}{l}\text { Normal birth } \\
\text { weight }(>2.5 \mathrm{~kg})\end{array}$ & $\begin{array}{l}\text { Low birth weight } \\
(2.5-1.5 \mathrm{~kg})\end{array}$ & $\begin{array}{l}\text { Very low birth } \\
\text { weight }(\mathbf{1 . 5}-1 \mathrm{~kg})\end{array}$ & $\begin{array}{l}\text { Extremely low birth } \\
\text { weight }(<1 \mathrm{~kg})\end{array}$ \\
\hline Central placenta & $44(55.7 \%)$ & $6(31.6 \%)$ & $1(33.3 \%)$ & 0 \\
\hline Lateral placenta & $35(44.3 \%)$ & $13(68.4 \%)$ & $2(66.6 \%)$ & $1(100 \%)$ \\
\hline Total & $\mathbf{7 9}$ & $\mathbf{1 9}$ & $\mathbf{3}$ & $\mathbf{1}$ \\
\hline
\end{tabular}

Table 14: Predictive value of placental position in predicting preeclampsia.

\begin{tabular}{|lll|}
\hline Placental position & Preeclampsia & Normotensive \\
\hline Central & $4(\mathrm{~A})$ & $47(\mathrm{~B})$ \\
\hline Lateral & $17(\mathrm{C})$ & $34(\mathrm{D})$ \\
\hline
\end{tabular}

There were $13(68.4 \%)$ out of 19 babies in low birth weight group were born to mothers with lateral placenta while $2(66.6 \%)$ out of 3 with very low birth weight also belonged to patients with lateral placenta. $100 \%$ of extremely low birth weight babies were from lateral placenta group.

- $\quad$ Sensitivity: $C / A+C * 100=80.9 \%$

- Specificity: $\mathrm{B} / \mathrm{D}+\mathrm{B} * 100=58 \%$

- $\quad$ Positive predictive value: $\mathrm{C} / \mathrm{C}+\mathrm{D} * 100=33.3 \%$

- Negative predictive value: $\mathrm{B} / \mathrm{B}+\mathrm{A} * 100=92.1 \%$

- $\quad \mathrm{P}$ value is $<0.001$ which is highly significant.

- Odds ratio is 5.875 .

Relative risk of developing preeclampsia with lateral placenta is 4.25 .

\section{DISCUSSION}

Preeclampsia, the most common medical complication of pregnancy continues to be one of the leading causes of maternal morbidity and mortality. Women with mild and moderate degrees of gestational hypertension can often be treated conservatively and delivered at or near term with good perinatal outcome. However, severe cases often warrant iatrogenic premature delivery in view of maternal interests. This often means compromising on the baby, with increase in perinatal morbidity and mortality. ${ }^{15}$

Various screening tests have been proposed for the prediction of preeclampsia with varying results. Some of these tests have shown potential as practical early screening test for the prediction of preeclampsia and related complications of pregnancy. Currently, there are no prospective studies or randomized trials which evaluate the benefits and risks of first trimester screening for prediction of preeclampsia. ${ }^{16}$

In this study, we have made an attempt to analyses the efficacy of the placental location, rather laterality, as determined by ultrasonography done at 18-24 weeks in predicting women at risk of developing preeclampsia.

In this study 102 patients were registered. Out of which 51 were in the central placenta group and 51 in lateral placenta group. Of the 102 patients, 21 developed preeclampsia with incidence of $20.5 \%$ which is slightly higher than other studies because of decent sample size.

Table 1 and 4 show women of different age were included in the study in both the groups. $85.7 \%$ of those who developed preeclampsia were in the age group of between 19-30 years. This is in accordance with MACGILLVIRAY'S report on age incidence of preeclampsia which states that the incidence of preeclampsia is high among young primigravida. $4.7 \%$ of those who developed preeclampsia were in the age group more than 30 years. Observation showed that maximum predisposition is between 19-30 years of age.

Thus, this study is comparable to other studies in terms of age incidence.

Table 2 and 5 show the distribution of patients developing preeclampsia on the basis of gravida status. The incidence of preeclampsia is high in primigravida when compared to multigravida. The overall incidence of preeclampsia in this study was $20.5 \%$. The overall incidence of preeclampsia in primigravida in this study was $15.6 \%$.

In this study out of 21 patients developing preeclampsia, $76.19 \%$ were primigravida, $14.28 \%$ were gravida 2 and $9.52 \%$ were gravida $3+$ thus showing highest incidence of preeclampsia amongst primigravida.

Table 3 shows the incidence of preeclampsia in both central and lateral placenta group.

In a study by Kore SJ et al, on prediction of preeclampsia development by placental location, out of the 200 women, 32 developed Preeclampsia/Gestational hypertension giving an incidence of $16 \%$. Nineteen of these 32 cases had lateral placenta and 13 had central placenta. Thus $59.38 \%$ women who developed preeclampsia had a laterally situated placenta while $40.62 \%$ women had a centrally situated placenta. The 
sensitivity, specificity, positive predictive value and negative predictive value were $59.38 \%, 88.10 \%, 48.72 \%$ and $91.93 \%$ respectively. ${ }^{15}$

In a study by Kakkar et al, out of 150 women, $84(56 \%)$ females had laterally located placenta and 66 (44\%) had centrally located placenta. Out of the 84 women with laterally located placenta, $56(66.6 \%)$ developed PIH whereas out of 66 women with centrally located placenta only 24 (36.6\%) developed PIH. The overall risk of developing PIH with laterally located placenta was 5.09 (odds ratio) and $95 \%$ CI 2.40-10.88. The difference was found to be highly significant statistically $(\mathrm{p}=0.00002) .{ }^{18}$

In a retrospective study by Keshavarz $\mathrm{E}$ et al, analysis showed lateral placenta was associated with preeclampsia in $47.6 \%$ (20 out of 42 ) of cases while other locations were associated with preeclampsia in $30 \%$ (101 out of 337) ( $\mathrm{P}$ Value $=0.02$, Odds ratio: $2.1,95 \%$ confidence interval: $1.1-4.1){ }^{19}$

In a study by Pai MV, Pillai J, a total of 426 unselected singleton pregnant women attending the antenatal clinic were included. A total of 71 women developed preeclampsia, of which $52(74 \%)$ had unilaterally located placenta at 20-24 weeks. This relationship was statistically highly significant $(\mathrm{P}<0.0001) .{ }^{20}$

In our study, out of 102 patients, 21 patients developed preeclampsia, out of which $17(80.9 \%)$ were from lateral placenta group and only $4(19.1 \%)$ were from central placenta group. Sensitivity of this study is $80.9 \%$ while specificity is $58 \%$. p value is $<0.001$, Odds ratio is 5.875 and relative risk for development of preeclampsia in patients with lateral placenta is 4.25 .

Table 6 depicts distribution of patients developing preeclampsia on the basis of severity of disease.

A study done by Sandhya et al, in 2015 on 300 patients suggests that $92.8 \%$ patients with severe preeclampsia had laterally located placenta and only $7.14 \%$ patients with severe preeclampsia had central placenta. $74 \%$ of patients with moderate preeclampsia had laterally located placenta. $^{17}$

Another study by Kakkar et al, on 150 patients showed that all the patients developing severe preeclampsia had laterally located placenta while amongst patients developing moderate preeclampsia, $71.4 \%$ had lateral placenta. $58.9 \%$ of patients with mild preeclampsia had lateral placenta. ${ }^{18}$

In this study, $80 \%$ of patients developing severe disease had lateral placenta and only $20 \%$ patients with severe disease had central placenta thus showing the comparable results with other studies and concluding that lateral location of placenta not only predisposes for preeclampsia but also increases its severity.
Tables 7-13 compare perinatal outcome in patients with lateral and central placenta in terms of timing of termination of pregnancy (term/preterm delivery), number of patients requiring caesarean section, APGAR score of babies at 1 and 5 minutes, need for NICU admission and predisposition for low birth weight and IUGR.

Study done by Keshavarz E et al showed, in the preeclampsia group, $80 \%$ of females underwent caesarean section compared to $66.5 \%$ in the normal group, which yielded a significant difference $(\mathrm{P}=0.005)$. Similarly, low birth weight (below 2500g) in the preeclampsia group was $47.3 \%$ while this was $4.7 \%$ in normal subjects ( $P$ $<0.001)$. The mentioned data revealed that preeclampsia pregnancies had more antepartum and intrapartum complications than the non-preeclampsia group. ${ }^{19}$ Also, caesarean section and low birth weight were more commonly seen in the lateral placenta group compared to the central placenta group.

In another retrospective study by Lucy Emily suggests that lateral placentation predisposes to IUGR and thus poor perinatal outcome. 69 pregnancies with IUGR were compared with 258 non IUGR pregnancies. Odds ratio was 4.6. IUGR pregnancies were 4 times more likely to have unilateral placenta. ${ }^{21}$

Kofinas et al found that in the presence of preeclampsia or IUGR $75 \%$ pregnancies had lateral placenta and $25 \%$ had central placenta. ${ }^{22}$

Similarly, Vaillant et al found an increased history of foetal distress, 29 caesarean deliveries, and IUGR in women with unilateral placentas compared with centrally implanted placentas. $^{23}$

In our study, perinatal outcome was poor in patients with lateral placenta. $62.5 \%$ of the total preterm deliveries in this study were associated with lateral placenta and $62.8 \%$ of the total caesarean sections were associated with patients with lateral placenta. $85.7 \%$ of total NICU admissions were for babies born to patients with lateral placenta. Also $100 \%$ of babies with poor APGAR score $(<3)$ at 1 and 5 minutes were born to mothers with lateral placenta. $75 \%$ and $80 \%$ of babies with moderate APGAR score (4-6) at 1 minute and 5 minutes respectively were born to patients with lateral placenta, while $53.2 \%$ of babies with good APGAR score (>7) belonged to patients having central placenta. $66.6 \%$ of babies with very low birth weight $(1-1.5 \mathrm{~kg}$ ) and $68.4 \%$ of babies with low birth weight $(1.5-2.5 \mathrm{~kg})$ were born to patients with lateral placenta.

So, the current study verified that lateral placenta was more commonly related to inappropriate complications of delivery, such as low birth weight and caesarean section and poor APGAR score at birth and need for NICU admission. 
Table 14 shows predictive value, sensitivity and specificity of this study as screening test.

Sensitivity was $80.9 \%$, specificity was $58 \%$, and Positive predictive value (PPV) of $33.3 \%$ and Negative predictive value (NPV) of $92.1 \%$. In assessing the placental location, lateral placenta had a meaningful effect with $p$ value $<0.001$.

Thus, ultrasound examination for location of placenta between 18-24 weeks of gestation is a safe, easily available, and accurate method in routine prenatal care. It is a simple predictor of preeclampsia and perinatal outcome.

\section{CONCLUSION}

The exact aetiology of preeclampsia is unknown, yet it is thought to be associated with abnormal blood flow of placenta. Recent evidence suggests the assessment of some factors in the first trimester, such as resistance index of uterine artery (RI index) and serum markers, such as HCG or PAPP-A for predicting preeclampsia but none of them are proven to be safe and reliable.

The current study was conducted to investigate placental location in routine ultrasonography exam, performed at second trimester of pregnancy, and determine whether this could be a simple predictor of development of preeclampsia in the third trimester.

The study shows that placental position determined by ultrasonography between 18-24 weeks of gestation is an excellent screening tool for the prediction of preeclampsia among numerous screening tests with specificity of $58 \%$ and sensitivity of $81 \%$. As yet, there is no practical, acceptable and reliable screening test for preeclampsia that has been thoroughly tried and tested. Most of pregnant women undergo USG between 18-20 weeks gestation to rule out congenital anomalies. Placental localisation in the same setting does not add to the cost of screening procedure.

\section{This test is a better screening test because}

- Simple and easy to perform

- Inexpensive and can be done along with anomaly scan

- Non-invasive and convenient for the patient.

Lateral placentation helps identify the population who is at greatest risk to be included in primary prevention program.

Thus, placental laterality as determined by ultrasound between 18-24 weeks; alone or with age and parity is a simple yet reliable and cost-effective predictive screening test for development of preeclampsia, and should be offered to all pregnant women attending antenatal clinic. However, the only set back of this study is humble sample size and therefore more of such studies and randomized trials should be done on larger population to further confirm the results of this study.

Funding: No funding sources

Conflict of interest: None declared

Ethical approval: The study was approved by the Institutional Ethics Committee

\section{REFERENCES}

1. Kuklina EV, Ayala C, Callaghan WM. Hypertensive disorders and severe obstetric morbidity in the United States. Obstet Gynecol. 2009;113(6):1299306.

2. WHO, World Health Statistics, 2012. Available at: https://www.who.int/healthinfo/EN_WHS2012_Part 3.pdf. Accessed on $5^{\text {th }}$ September 2018.

3. Organization, W, Bank W, Fund U. Maternal mortality in 2005: estimates developed by WHO, UNICEF, UNFPA, and The World Bank, 2007. Available at: https://apps.who.int/iris/handle /10665/43807. Accessed on $1^{\text {st }}$ September 2018.

4. Studd J, Baker F. Screening tests for pregnancy induced hypertension in progress. Obstet Gynecol. 1990;10:69.

5. Walker JJ. Current thoughts on the pathophysi ology of preeclampsia/eclampsia. In: Studd J, editor. Progress in obstetrics and gynecology. Edinburgh: Livingstone-Churchill; 1998:177-88.

6. Fleischer A, Schulman H, Farmakides G. Uterine artery Doppler velocimetry in pregnant women with hypertension. Am J Obstet Gynecol. 1986;154:80613.

7. Schulman H, Winter D, Farmakides G. Pregnancy surveillance with Doppler velocimetry of uterine and umbilical arteries. Am J Obstet Gynecol. 1989;160:192-6.

8. Belogolovkin V, Engel SM, Ferrara L, Eddleman KA, Stone JL. Does sonographic determination of placental location predict fetal birth weight in diamniotic-dichorionic twins? J Ultrasound Med. 2007;26(2):187-91.

9. Guiot C, Gaglioti P, Oberto M, Piccoli E, Rosato R, Todros T. Is threedimensional power Doppler ultrasound useful in the assessment of placental perfusion in normal and growth-restricted pregnancies? Ultrasound Obstet Gynecol. 2008;31(2):171-6.

10. Chhabra S, Yadav Y, Srujana D, Tyagi S, Kutchi I. Maternal neonatal outcome in relation to placental location, dimensions in early pregnancy. J Basic Clin Reprod Sci. 2013;2(2):105-9.

11. Moore RJ, Strachan BK, Tyler DJ, Duncan KR, Baker PN, Worthington BS, et al. In utero perfusing fraction maps in normal and growth restricted pregnancy measured using IVIM echo-planar MRI. Placenta. 2000;21(7):726-32. 
12. Francis ST, Duncan KR, Moore RJ, Baker PN, Johnson IR, Gowland PA. Non-invasive mapping of placental perfusion. Lancet. 1998;351(9113):1397-9.

13. Zia S. Placental location and pregnancy outcome. J Turk German Gynecol Assoc. 2013;14(4):190.

14. Van E Beek, Peters LLH. Pathogenesis of preeclampsia. A comprehensive model. Obstet Gynaecol Survey. 1998;53(4):233-9.

15. Kore S, Khot R, Supe P, Kanavia D, Thunga C, Nandanwar Y. Prediction of pre-eclampsia: role of placental laterality by ultrasonography. Int J Repro Contracept Obstet Gynaecol. 2016:1433-1437.

16. Sibai BM. First-trimester screening with combined maternal clinical factors, biophysical and biomarkers to predict preterm pre-eclampsia and hypertensive disorders: are they ready for clinical use? BJOG. 2015;122(3):282-3.

17. Sandhya, G Madhavi. Placental laterality as a predictor of preeclampsia. Am J Phytomed Clin Therap. 2015;3(3):231-6.

18. Kakkar T, Singh V, Razdan R, Digra S, Gupta A, Kakkar M. Placental laterality as a predictor for development of preeclampsia. J Obstet Gynaecol India. 2012;63(1):22-5.

19. Keshavarz E, Sadeghian A, Ganjalikhan Hakemi A, TalebiKhtibi F. Prediction of preeclampsia development by placental location: a simple predictor. J Obstet Gynaecol Cancer Res. 2017;2:4.

20. Muralidhar P, Jothi P. Placental laterality by ultrasonogram a simple yet reliable predictive test for pre-eclampsia prediction. J Obstet Gynecol. 1989;161:153-69.

21. Kalanithi LE, Illuzzi JL, Nossov VB. Intrauterine growth restriction and placental location. J Ultrasound Med. 2007;26:1481-9.

22. Kofinas AD, Penry M, Swain M, Hatjis CG. Effect of placental laterality on uterine artery resistance and development of preeclampsia and intrauterine growth retardation. Am J Obstet Gynecol. 1989;161:1536-9.

23. Vaillant P, Best MC, Cynober E, Devulder G. Pathological Doppler uterine readings when the placenta is laterally situated. J Gynecol Obstet Biol Reprod. 1993;22:301-7.

Cite this article as: Uikey $\mathrm{P}$, Gurwani V, Tajne M.

Correlation between placental location and

development of preeclampsia. Int J Reprod

Contracept Obstet Gynecol 2019;8:4155-62. 